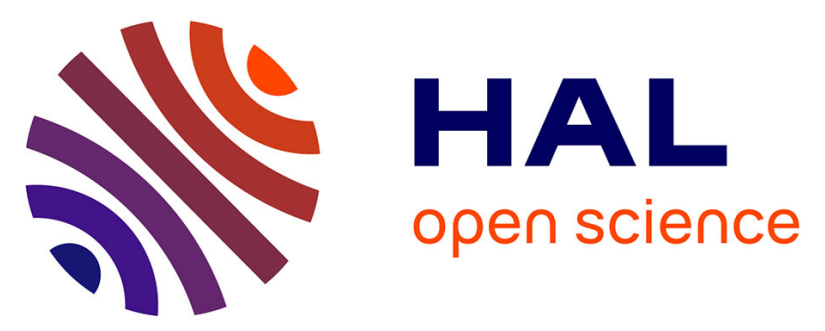

\title{
Patterns of recurrence and prognosis in locally advanced FIGO stage IB2 to IIB cervical cancer: Retrospective multicentre study from the FRANCOGYN group
}

Tiphaine de Foucher, Sofiane Bendifallah, Lobna Ouldamer, Alexandre

Bricou, Vincent Lavoué, Justine Varinot, Geoffroy Canlorbe, Xavier

Carcopino, Emilie Raimond, Laurie Monnier, et al.

\section{To cite this version:}

Tiphaine de Foucher, Sofiane Bendifallah, Lobna Ouldamer, Alexandre Bricou, Vincent Lavoué, et al.. Patterns of recurrence and prognosis in locally advanced FIGO stage IB2 to IIB cervical cancer: Retrospective multicentre study from the FRANCOGYN group. EJSO - European Journal of Surgical Oncology, 2019, 45 (4), pp.659-665. 10.1016/j.ejso.2018.11.014 . hal-02468510

\author{
HAL Id: hal-02468510 \\ https://hal.science/hal-02468510
}

Submitted on 22 Oct 2021

HAL is a multi-disciplinary open access archive for the deposit and dissemination of scientific research documents, whether they are published or not. The documents may come from teaching and research institutions in France or abroad, or from public or private research centers.
L'archive ouverte pluridisciplinaire HAL, est destinée au dépôt et à la diffusion de documents scientifiques de niveau recherche, publiés ou non, émanant des établissements d'enseignement et de recherche français ou étrangers, des laboratoires publics ou privés.

\section{(ㅇ)(1) $\$$}

Distributed under a Creative Commons Attribution - NonCommerciall 4.0 International 
Patterns of recurrence and prognosis in locally advanced FIGO stage IB2 to IIB cervical cancer: retrospective multicentre study from the FRANCOGYN Group.

Short version of title: Recurrence and prognosis for locally advanced cervical cancer

Tiphaine de FOUCHER (M.D), Sofiane BENDIFALLAH (M.D, PhD) ${ }^{1,2}$, Lobna OULDAMER (M.D, PhD) ${ }^{3}$, Alexandre BRICOU (M.D.) ${ }^{4}$, Vincent LAVOUE (M.D, PhD) ${ }^{5}$, Justine VARINOT (M.D) ${ }^{6}$, Geoffroy CANLORBE (M.D) ${ }^{1}$, Xavier CARCOPINO (M.D, PhD) ${ }^{7}$, Emilie RAIMOND (M.D) ${ }^{8}$, Laurie MONNIER (M.D) ${ }^{1}$, Olivier GRAESSLIN (M.D, PhD) ${ }^{8}$, Cyril TOUBOUL (M.D, PhD) ${ }^{9}$, Pierre COLLINET (M.D, PhD) ${ }^{10}$, Marie-Emmanuelle NEVEU (M.D) ${ }^{11}$, Cyrille HUCHON (M.D, PhD) ${ }^{12}$, Emile DARAï (M.D, PhD) ${ }^{1,13}$, Marcos BALLESTER (M.D, PhD) ${ }^{1,13}$

For the Groupe de Recherche FRANCOGYN, FRANCE.

1. Department of Gynaecology and Obstetrics, Tenon University Hospital, Assistance Publique des Hôpitaux de Paris (AP-HP), University Pierre and Marie Curie, Paris 6, Institut Universitaire de Cancérologie (IUC), 4 rue de la Chine, 75020 Paris France.

2. INSERM UMR_S_707, "Epidemiology, Information Systems, Modeling", University Pierre and Marie Curie, Paris 6, 27 rue de Chaligny, 75012 Paris, France.

3 Department of Obstetrics and Gynaecology, Centre Hospitalier Régional Universitaire de Tours, Hôpital Bretonneau, 2 bd Tonnellée, 37000 Tours, France.

4 Department of Obstetrics, Gynecology and Reproductive Medicine, Hôpitaux Universitaires Paris Seine Saint-Denis, Assistance Publique-Hôpitaux de Paris, av du 14 juillet, 93140 Bondy, France.

5 CRLCC Eugène-Marquis, service de gynécologie, CHU de Rennes, université de Rennes 1, av de la bataille Flandres-Dunkerque, 35000 Rennes, France.

6 Department of Pathology, Tenon University Hospital, Assistance Publique des Hôpitaux de Paris (AP-HP), University Pierre and Marie Curie, Paris 6, 4 rue de la Chine, 75020 Paris, France.

7 Department of Obstetrics and Gynaecology, Hôpital Nord, APHM, Aix-Marseille University (AMU), CNRS, IRD, chemin des Bourrely, 13105 Marseille, France.

8 Department of Obstetrics and Gynaecology, Institute Alix de Champagne University 
Hospital, 45 rue Cognacq Jay, 51100 Reims, France.

9 Department of Obstetrics and Gynecology, Centre Hospitalier Intercommunal, Créteil, 40 av de Verdun, 94000 Créteil, France.

10 Department of Gynecologic Surgery, Jeanne de Flandre Hospital, CHU de Lille, av Eugène Avinée, 59000 Lille, France.

11 Department of Gynecology and Obstetrics, Kremlin-Bicêtre University Hospital, 78 rue du Général Leclerc, 94170 Le Kremlin-Bicêtre, France.

12 Department of Obstetrics and Gynecology, Poissy-St Germain Hospital, 10 rue du champ Gaillard, 78000 Poissy, France.

13 INSERM UMR_S_938, University Pierre et Marie Curie, Paris 6, 27 rue de Chaligny, 75012 Paris, France.

Conflicts of interest: the authors report no conflict of interest.

Funding: No external funding source

Corresponding author : Sofiane BENDIFALLAH, MD, PhD Service de Gynécologie-Obstétrique Hôpital Tenon, 4 rue de la Chine, 75020 Paris, France Phone: + 33156016876 Fax: + 33156016062

E-mail: sofiane.bendifallah@aphp.fr

Word counts : abstract : 231, main text : 2838. 


\section{Abbreviations:}

BMI: body mass index

CC: cervical cancer

CCRT: concomitant chemo-radiotherapy

Cls: confidence intervals

DR: distant recurrence

FIGO: International Federation of Gynecology and Obstetrics

HT: first radical hysterectomy

INCa: French National Institue of Cancer

LACC: locally advanced cervical cancer

LN: lymph node

LRR: local regional recurrence

LVSI: Iympho-vascular space invasion

MRI: Magnetic Resonance Imaging

OS: Overall survival

PAL: para-aortic lymph node dissection

PET-CT: Positron Emission Tomography-Computed Tomography

RFS: recurrence free survival

VBT: vaginal brachytherapy 


\section{ABSTRACT}

Introduction: Evidence-based data describing patterns of recurrence and prognosis in women with FIGO stage IB2 to IIB locally advanced cervical cancer (LACC) are scarce. The purpose of this study was to analyse patterns of recurrence in LACC and their correlation with prognosis, depending on FIGO stage, lymph node (LN) status and treatment modalities. The endpoints of this study were the type of recurrence (locoregional or distant, and time to recurrence), the recurrence free survival, the overall survival and the cumulative incidence for both locoregional and distant recurrence.

Materials and Methods: Data of women with FIGO stage IB2 to IIB CC treated between April 1996 and May 2016 were retrospectively abstracted from nine French institutions.

Results: The median follow-up for the 501 women included was 35.6 months. Recurrences were observed in 158 (31.5\%), with a mean time to recurrence of 20.7 months. Women with IIB CC had poorer prognosis, lower 3-year RFS and higher 3year cumulative incidence of both locoregional and distant recurrences. Women with positive or unknown LN status had poorer prognosis with higher 3-year cumulative incidence of distant recurrence. Women who underwent concomitant chemo-radiotherapy +/- vaginal brachytherapy had poorer prognosis, with lower 3year RFS and higher 3-year cumulative incidence of distant recurrence.

Conclusions: Recurrence location and time to recurrence differ widely depending on the FIGO stage, LN status and treatment modalities, with potential impact on followup modalities and therapeutic approaches.

Key words: locally advanced cervical cancer, recurrence, pattern, survival 


\section{INTRODUCTION}

Cervical cancer (CC) is the fourth most common cancer in women, with an estimated worldwide incidence of 527600 and a death rate of 265700 reported in 2015 [1). In women with FIGO (International Federation of Gynecology and Obstetrics) stage IB2 to IIB locally advanced cervical cancer (LACC), recurrences have been reported to occur in $15 \%$ to $40 \%$, with a 5 -year recurrence-free survival (RFS) averaging from $50 \%$ to $70 \%[2][3][4][5][6]$.

It is now well established that most events in CC are observed within 2 years following the diagnosis [7]. Recurrences after primary treatment are often located in the true pelvis, but other locations including distant recurrences or peritoneal carcinomatosis can also be observed underlining the prognostic heterogeneity of the disease [8][9][10][11]. To reduce this heterogeneity, several epidemiological, histological and treatment prognostic factors for recurrence and survival have been reported and are currently used to define optimal CC management [12][13]. In this setting, different models have been developed based on the prognostic factors to predict recurrence and survival in LACC [6][14][15][16]. However, to date, few evidence-based data are available about patterns of recurrence (location, timing from initial treatment) and prognosis for FIGO stage IB2 to IIB CC. As a result, LACC management guidelines from various countries are heterogeneous, especially concerning: (i) the prognostic and therapeutic value of surgical nodal staging, (ii) the optimal treatment modalities, and (iii) the rationale of post-operative follow-up [17][18][19][20][21].

The aim of the study was to analyse pattern of recurrence in women with LACC based on a large retrospective French multicentre database. Analyses were stratified according to FIGO stage, lymph node (LN) status and treatment modalities.

\section{MATERIAL AND METHODS}

\section{Study population}

The data of women with histologically proven FIGO stage IB2 to IIB CC treated between April 1996 and May 2016 were retrospectively abstracted from nine institutions with prospectively maintained CC databases in France (Tenon University 
Hospital, Tours University Hospital, Creteil University Hospital, Reims University Hospital, Rennes University Hospital, Jeanne de Flandre University Hospital, Poissy University Hospital, Jean Verdier Hospital and Marseille North University Hospital). All the women had given written consent to participate in the study, and the research protocol was approved by the Institutional Review Board of the Collège National des Gynécologues et Obstétriciens Français (CEROG 2016-GYN-0502).

All enrolled women underwent pre-operative workup including history, physical examination, cervical biopsy, Magnetic Resonance Imaging (MRI) and Positron Emission Tomography-Computed Tomography (PET-CT), if indicated according to the FIGO stage and the period of treatment. Cystoscopy and/or proctoscopy were performed if there was a suspicion of bladder or rectal involvement after clinical examination or on MRI.

Clinical, surgical and pathological data as well as details of adjuvant therapies were collected: the woman's age, body mass index (BMI; calculated as weight in kilograms divided by the square of height in meters), surgical procedure (type of hysterectomy and/or LN staging), FIGO stage, final pathological analysis (histological type, tumour grade, tumour size and lympho-vascular space invasion (LVSI) status), treatment modalities and prognosis (recurrence, death). All women were classified according to the $2009 \mathrm{FIGO}$ classification [22].

\section{Therapeutic management}

Therapeutic management was decided on by a multidisciplinary committee on an individual basis, according to the French National Institue of Cancer (INCa) guidelines [21], depending on FIGO stage and results of PET-CT when available. When indicated, laparoscopic LN staging was performed including para-aortic (PAL) +/- pelvic lymph node dissection. We applied the following definitions to describe the LN status: women were considered as node positive when they had metastatic LNs on PET-CT or after surgical nodal staging; as node negative when they had disease free LN on surgical nodal staging; and as nodal status unknown if neither PET-CT nor surgical staging had been performed or with negative PET-CT but without surgical nodal staging.

Clinical follow-up consisted of physical examinations and the use of imaging 
techniques according to the findings. Follow-up sessions were conducted every 3 months for the first 2 years, every 6 months for the following 3 years, and once a year thereafter.

\section{Definition and classification of recurrence}

Recurrent disease was assessed by physical examination, imaging techniques and biopsy when feasible.

According to a previous report [23], we applied the following definition to describe the patterns of recurrence: local regional recurrence (LRR) was defined recurrences including (i) the cervix, (ii) the vaginal vault, (iii) pelvic LNs, and (iv) the pelvic walls. Distant recurrence (DR) could include (i) metastatic spread to organs whatever the location, (ii) peritoneal carcinomatosis and (iii) extra pelvic LN involvement.

RFS was defined as the time from the date of primary treatment to any CC recurrence and was censored at the date of last follow-up or death without recurrence. Overall survival (OS) was defined as the time from primary treatment to death as a result of any cause.

\section{Statistical analysis}

The women's characteristics, and tumour and treatment characteristics were analysed using Chi-square statistics or Fisher's exact test for categorical variables and the t-test or analysis of variance (ANOVA) for continuous variables. KaplanMeier estimates were used to estimate the event-time distributions, and log-rank test was used to compare the differences among the different groups in terms of RFS and OS. The kernel-smoothed hazard functions of RFS were estimated on the basis of the method described by Cardoso et al. [24]. Time to the first CC recurrence for a specific site was evaluated by cumulative incidence analysis (Gray's test) and competing risk regression analysis to estimate sub- distribution hazard ratios (HRs) and $95 \%$ confidence intervals (Cls). Analysis was stratified according to FIGO stage, LN status and treatment modalities. Values of $p<0.05$ were considered to denote significant differences. Data were managed with an Excel database (Microsoft, Redmond, WA, USA) and analysed using the R $2 \cdot 15$ software, available online. 


\section{RESULTS}

\section{Epidemiological and surgical characteristics of the population.}

During the study period, 501 women with FIGO stage IB2 to IIB LACC were documented as having received treatment. Recurrences were observed in 158 (31.5\%): 72 were LRR and 86 DR (among which 20 were both LRR and DR). The study flow chart is shown in Figure 1. Epidemiological and histological characteristics of the population are reported in Table 1.

\section{OS and RFS according to FIGO stage, LN status and treatment modalities.}

The median follow-up was 35.6 months (1.1-146.5 months). In the whole population, the respective 3-year OS and RFS were $83.5 \%(95 \% \mathrm{Cl}, 79.8-87.3)$ and $67.4 \%(95 \% \mathrm{Cl}, 63.1-72.1), p<0,05$. The respective 3 -year OS according to recurrence location were $66.1 \%(95 \% \mathrm{Cl}, 54.4-80.3)$ for $\mathrm{LRR}$ and $56.1 \%(95 \% \mathrm{Cl}, 45.2-$ 69.6) for DR.

The respective 3-year RFS for women with FIGO stages IB2, IIA and IIB were 79.1\% (95\% Cl, 69.5 - 89.9), 79.1\% (95\% Cl, 70.2 - 89.1) and 62.0\% (95\% Cl, $56.6-$ 68.0), respectively, $(p<0.001)$. No difference was found in 3 -year OS according to FIGO stage.

The respective 3-year OS were $87.1 \%$ (95\% Cl, 82.4 - 92.0), 78.7\% (95\% Cl, 71.9 - 86.1) and $81.7 \%(95 \% \mathrm{Cl}, 72.4$ - 92.3), for node negative women, node positive women and those with unknown LN status, respectively $(p<0.001)$. The respective 3-year RFS were $76.8 \%(95 \% \mathrm{Cl}, 71.1-82.9), 58.4 \%(95 \% \mathrm{Cl}, 50.7-67.3)$, and $61.8 \%$ $(95 \% \mathrm{Cl}, 51.2-74.5)$, for node negative women, node positive women and those with unknown LN status, respectively $(p<0.0001)$.

The respective 3-year OS were 90.7\% (95\% Cl, 82.3 - 99.9), 85.2\% (95\% Cl, 80.1 - 90.7) and $79.1 \%(95 \% \mathrm{Cl}, 73.0-85.8)$, for women who underwent a first radical hysterectomy $(\mathrm{HT})$ +/- concomitant chemo-radiotherapy (CCRT) +/- vaginal brachytherapy (VBT), CCRT +/- VBT followed by radical HT and CCRT +/- VBT, respectively $(p<0.01)$. The respective 3 -year RFS were $75.8 \%(95 \% \mathrm{Cl}, 64.9-88.5)$, $74.3 \%(95 \% \mathrm{Cl}, 68.1-81.1)$ and $59.2 \%(95 \% \mathrm{Cl}, 52.3-65.6)$, for women who underwent a first radical HT +/- CCRT +/- VBT, CCRT +/- VBT followed by radical HT 
and CCRT +/- VBT, respectively $(p<0.0001)$.

As reported in Table 2, after multivariate analysis FIGO stage and LN status remain significant independent risk factors for recurrence.

\section{Cumulative incidence for LRR and DR according to FIGO stage, LN status and} treatment.

Overall, recurrences were observed in 158 of the 501 women (31.5\%). The mean time to recurrence was 20.72 months (3-122months). The 3-year cumulative incidences of LRR and DR in the whole population were $16.1 \%$ and $18.8 \%$, respectively.

The 3-year cumulative incidence rates and their distribution according to FIGO stage, LN status and treatment modalities are reported in Figure 2 ( $A, B, C, D$, E, F). Women with FIGO stage IIB CC had a higher 3-year cumulative incidence for both LRR and DR than women with FIGO stage IIA or IB2 CC $(19.4 \%$ and $22.4 \%$ vs. $12.5 \%$ and $9.6 \%$, and $7.4 \%$ and $13.4 \%$ respectively, $p<0.01$ ). Node positive women and women with unknown LN status had a higher 3-year cumulative incidence of DR than node negative women $(29.1 \%$ and $25.1 \%$ vs. $10.7 \%, p<0.001)$. No significant difference in LRR was observed according to LN status. Women treated with CCRT +/- VBT had a higher 3-year cumulative incidence of DR than women treated with CCRT+/-VBT followed by radical HT or first radical HT +/- CCRT +/- VBT (27.8\% (95\% $\mathrm{Cl}, 20.3-34.6), 13.9 \%(95 \% \mathrm{Cl}, 8.4-19)$ and $7.1 \%(95 \% \mathrm{Cl}, 1-13.6), \mathrm{p}<0.001)$. No significant difference in LRR was observed according to treatment modalities.

\section{DISCUSSION}

This study reports specific site and time patterns of first recurrence for LACC according to the main prognostic factors (i.e. FIGO stage and LN status) and treatment modalities. Our results confirm that FIGO stage IIB, positive LNs as well as unknown LN status are major prognostic factors which affect the time to first recurrence and site as well as the HR for recurrence. Such results are of interest to adapt long-term clinical follow-up and as a starting point to improve therapeutic management of LACC.

LN status is known to be a major prognostic factor for all stages of CC [5]. 
However, the prognostic impact of surgical LN staging in the standard management of FIGO stage IB2 to IIB CC remains to be proved, as published results concerning the superiority of surgical over radiological staging are contradictory [25] [26]. For example, Lai et al. found no benefit of surgical staging in a randomized controlled trial comparing surgical to clinical staging. In contrast, Gold et al. found that surgical exclusion of positive para-aortic LNs in patients with LACC who received chemoradiation had a significant prognostic impact compared with radiographic exclusion. In our study, $60 \%$ of the women underwent radiological nodal staging and 72\% surgical nodal staging, highlighting the considerable heterogeneity in practice within the same country. We found that women without optimal LN staging (i.e. with neither radiological nor surgical LN staging or with negative radiological staging and no surgical staging) had poorer 3-year RFS and OS, close to that of node positive women (61.8\% vs. $58.4 \%$ and $81.7 \%$ vs. $78.7 \%)$. We found no significant difference in LRR according to LN status, but a significantly higher rate of DR among node positive women and women without optimal LN staging than among node negative women $(29.1 \%$ and $25.1 \%$ vs. $10.7 \%)(p<0.001)$. For women with positive nodes, these results are consistent with literature [13]. Our results are of importance for women with unknown LN status, as surgical staging is currently considered a key procedure to plan the extent of radiation therapy (RT) strategy in France. Thus, we can hypothesize that some of the women without optimal LN staging were undertreated, explaining such a poor prognosis. In this setting, several authors have suggested performing systematic CCRT in all women with LACC, with a prophylactic extension of the radiation field to the para-aortic area regardless of the staging [26][27]. This latter option must be questioned in the light of our results, especially for women who did not undergo optimal nodal staging.

Although it is commonly accepted that the treatment of LACC is primarily based on CCRT [21], treatment guidelines are inconsistent [17][18][19][20][21] and the place of radical HT remains to be determined [28][29]. In our study, women treated with exclusive CCRT +/- VBT had poorer prognosis (with a lower 3-year RFS and a higher 3year cumulative incidence of DR) than women who underwent either first radical HT +/- CCRT +/- VBT or CCRT +/- VBT followed by radical rather than completion HT. Nevertheless, these results should be interpreted in the light of the LN status as 
French guidelines recommend exclusive CCRT +/- VBT for node positive women while completion HT is restricted to patients with negative lymph node status. Among the 222 women treated by exclusive CCRT +/- VBT, 97 (43.9\%) had positive LNs and 47 (21.2\%) had unknown LN status while among the 279 women who underwent other treatment modalities, 59 (21.1\%) had positive LNs and 38 (13.6\%) had unknown LN status. A meta-analysis studying the impact of adjuvant hysterectomy in patients with LACC treated with CCRTshowed no improval on OS, although hysterectomy seemed to reduce the risk of recurrence. Moreover, the author recomanded that routine use of hysterectomy should be avoided due to significant morbidity in these patients [30]. Legge $\mathrm{F}$ et al., after analyzing the patterns of recurrence and their association with clinical outcome in LACC patients submitted to primary chemoradiation followed by radical surgery, found most of the recurrences were outside the irradiated field (57.3\%). This is consistent with our results, as we observed $56,9 \%$ of DR. Among the parameters of recurrence associated with RFS they bring out, only secondary radical surgery retains an independent predictive role in reducing the risk of death $(p=0.037)$ [31]. Hence, future randomized trials are needed to clearly define the place of first intention radical HT and of completion HT in the treatment of FIGO stage IB2 to IIB CC.

A better knowledge of stage IB2 to IIB patterns of recurrence is also needed to adapt follow-up modalities as, to date, post-treatment monitoring programmes differ widely from country to country [32]. Current international guidelines recommend physical examination every 3-6 months for 2 years, then every 6 months or annually. Imaging studies are recommended when clinically indicated, testing for serum tumour markers is optional, and the frequency of the pap-smear test is controversial [18][19][20][21]. However, clinical examination alone seems to be insufficient as several authors report the low performance of clinical monitoring to detect asymptomatic recurrences. This suggests a need of prospective costeffectiveness studies as well as multilticentre randomized clinical trials to compare various follow-up policies [8][33][34]. Furthermore, there is limited evidence of a significant impact on survival of systematic regular CT scans or MRI for asymptomatic patients [35][36] [37] [39] [40]. Even though PET-CT has been shown to be useful in the diagnosis of recurrent $\mathrm{CC}$, especially in the case of unexplained elevation of 
serum tumour markers without evidence of recurrent disease on conventional workup [41], the exact indications of this exam in the setting of CC recurrence are yet to be defined. However, no study to date has focused on the follow-up modalities for women at increased risk of recurrence. Our results suggest that closer monitoring including systematic imaging procedures would be of benefit to these patients, especially for those with positive or unknown LN status.

The strengths of our study lie in its multicentre nature and the large number of women included, but some limits deserve to be mentioned. First, we cannot exclude an inherent bias linked its retrospective multicenter nature. Indeed, the guidelines changed during the period of data collection and PET-CT was introduced which incurred modification to the management strategy over the years. In the following retrospective long-term study especially concerning the surgical strategy of pelvic lymphadenectomy is not homogeneous. However, all included women were treated in regional referral centres applying French/European guidelines after systematic multidisciplinary committee approval. Second, there are considerable differences in describing the recurrences from study to study which could also bias the comparison of reported rates. Based on previous reports, we opted to combine cervical, vaginal vault, pelvic LN, and pelvic wall recurrences as LRR, and organ metastasis, peritoneal carcinomatosis and extra-pelvic LN recurrences as DR [23]. Third, even if our results allowed us to describe patterns of recurrences in LACC, they should be carefully analysed beyond 3 years before drawing any firm conclusion. Finally, our results are consistant with previous report. Indeed, Rose et al. and Ferrandina et al. also suggested that clinical stage and LN status were significantly associated with clinical outcomes [15] [42].

\section{CONCLUSION}

Our results show that the patterns of recurrence in women with LACC differ widely in terms of time to recurrence and site, depending on the FIGO stage, LN status and treatment modalities. We hypothesize that characterizing and understanding the behaviour of these tumours may have profound implications on treatment options and follow-up modalities. Thus our results could give rise to improved monitoring programmes and should be taken into account when designing 
future therapeutic approaches. 


\section{REFERENCES}

1. Ferlay J, Soerjomataram I, Dikshit R, Eser S, Mathers C, Rebelo M, et al. Cancer incidence and mortality worldwide: sources, methods and major patterns in GLOBOCAN 2012. Int J Cancer. 1 mars 2015;136(5):E359-386.

2. Delgado G, Bundy B, Zaino R, Sevin BU, Creasman WT, Major F. Prospective surgical-pathological study of disease-free interval in patients with stage IB squamous cell carcinoma of the cervix: a Gynecologic Oncology Group study. Gynecol Oncol. sept 1990;38(3):352 $\square 7$.

3. Inoue T, Morita K. The prognostic significance of number of positive nodes in cervical carcinoma stages IB, IIA, and IIB. Cancer. 1 mai 1990;65(9):1923 $\square 7$.

4. Takeda N, Sakuragi N, Takeda M, Okamoto K, Kuwabara M, Negishi H, et al. Multivariate analysis of histopathologic prognostic factors for invasive cervical cancer treated with radical hysterectomy and systematic retroperitoneal lymphadenectomy. Acta Obstet Gynecol Scand. déc 2002;81(12):1144 $\square 51$.

5. Quinn MA, Benedet JL, Odicino F, Maisonneuve P, Beller U, Creasman WT, et al. Carcinoma of the cervix uteri. FIGO 26th Annual Report on the Results of Treatment in Gynecological Cancer. Int J Gynaecol Obstet Off Organ Int Fed Gynaecol Obstet. nov 2006;95 Suppl 1:S43-103.

6. Polterauer S, Grimm C, Hofstetter G, Concin N, Natter C, Sturdza A, et al. Nomogram prediction for overall survival of patients diagnosed with cervical cancer. Br J Cancer. 4 sept 2012;107(6):918 $\square 24$.

7. Webb MJ, Symmonds RE. Site of recurrence of cervical cancer after radical hysterectomy. Am J Obstet Gynecol. 1 déc 1980;138(7 Pt 1):813 $\square 7$.

8. Ansink A, de Barros Lopes A, Naik R, Monaghan JM. Recurrent stage IB cervical carcinoma: evaluation of the effectiveness of routine follow up surveillance. $\mathrm{Br}$ J Obstet Gynaecol. nov 1996;103(11):1156 $\square$. 
9. Landoni F, Colombo A, Milani R, Placa F, Zanagnolo V, Mangioni C. Randomized study between radical surgery and radiotherapy for the treatment of stage IBIIA cervical cancer: 20-year update. J Gynecol Oncol. mai 2017;28(3):e34.

10. Lavoué $V$, Voguet $L$, Bertel $C$, Mesbah $H$, Williaume $D$, Laguerre $B$, et al. [Place of surgery before and after concurrent chemoradiotherapy for locally advanced cervical carcinoma: A retrospective study of 102 cases]. J Gynecol Obstet Biol Reprod (Paris). févr 2011;40(1):11 $\square 21$.

11. Carcopino X, Houvenaeghel G, Buttarelli M, Esterni B, Tallet A, Goncalves A, et al. Equivalent survival in patients with advanced stage IB-II and III-IVA cervical cancer treated by adjuvant surgery following chemoradiotherapy. Eur J Surg Oncol J Eur Soc Surg Oncol Br Assoc Surg Oncol. mai 2008;34(5):569 $\square 75$.

12. Burghardt E, Baltzer J, Tulusan AH, Haas J. Results of surgical treatment of 1028 cervical cancers studied with volumetry. Cancer. 1 août 1992;70(3):648 $\square 55$.

13. Stehman FB, Bundy BN, DiSaia PJ, Keys HM, Larson JE, Fowler WC. Carcinoma of the cervix treated with radiation therapy. I. A multi-variate analysis of prognostic variables in the Gynecologic Oncology Group. Cancer. 1 juin $1991 ; 67(11): 2776 \square 85$.

14. Shim S-H, Lee S-W, Park J-Y, Kim YS, Kim D-Y, Kim J-H, et al. Risk assessment model for overall survival in patients with locally advanced cervical cancer treated with definitive concurrent chemoradiotherapy. Gynecol Oncol. janv 2013;128(1):54 $\square 9$.

15. Rose PG, Java J, Whitney CW, Stehman FB, Lanciano R, Thomas GM, et al. Nomograms Predicting Progression-Free Survival, Overall Survival, and Pelvic Recurrence in Locally Advanced Cervical Cancer Developed From an Analysis of Identifiable Prognostic Factors in Patients From NRG Oncology/Gynecologic Oncology Group Randomized Trials of Chemoradiotherapy. J Clin Oncol. 1 juill 2015;33(19):2136. 
16. Yoon WS, Yang DS, Lee JA, Lee NK, Park YJ, Kim CY, et al. Validation of Nomograms for Survival and Metastases after Hysterectomy and Adjuvant Therapy in Uterine Cervical Cancer with Risk Factors. BioMed Res Int. 2017;2017:2917925.

17. Koh W-J, Greer BE, Abu-Rustum NR, Apte SM, Campos SM, Chan J, et al. Cervical cancer. J Natl Compr Cancer Netw JNCCN. 1 mars 2013;11(3):320 44.

18. PDQ Adult Treatment Editorial Board. Cervical Cancer Treatment (PDQ $\left.{ }^{\circledR}\right)$ : Health Professional Version. In: PDQ Cancer Information Summaries [Internet]. Bethesda (MD): National Cancer Institute (US); 2002 [cité 12 avr 2017]. Disponible sur: http://www.ncbi.nlm.nih.gov/books/NBK66058/

19. Colombo N, Creutzberg C, Amant F, Bosse T, González-Martín A, Ledermann J, et al. ESMO-ESGO-ESTRO Consensus Conference on Endometrial Cancer: diagnosis, treatment and follow-up. Ann Oncol. 1 janv 2016;27(1):16 $\square 41$.

20. Lim MC, Lee M, Shim SH, Nam EJ, Lee JY, Kim HJ, et al. Practice guidelines for management of cervical cancer in Korea: a Korean Society of Gynecologic Oncology Consensus Statement. J Gynecol Oncol. mai 2017;28(3):e22.

21. Haute Autorité de Santé - ALD n 30 - Cancer invasif du col utérin [Internet]. [cité 12 avr 2017]. Disponible sur: http://www.hassante.fr/portail/jcms/c_922973/fr/ald-n-30-cancer-invasif-du-col-uterin

22. Pecorelli S, Zigliani L, Odicino F. Revised FIGO staging for carcinoma of the cervix. Int J Gynaecol Obstet Off Organ Int Fed Gynaecol Obstet. mai 2009;105(2):107 $\square 8$.

23. Yang K, Park W, Huh SJ, Bae D-S, Kim B-G, Lee J-W. Clinical outcomes in patients treated with radiotherapy after surgery for cervical cancer. Radiat Oncol J Radiat Oncol J [Internet]. 12 déc 2016 [cité 24 mars 2017]; Disponible sur: http://www.e-roj.org/journal/view.php?doi=10.3857/roj.2016.01893 
24. Metzger-Filho O, Sun Z, Viale G, Price KN, Crivellari D, Snyder RD, et al. Patterns of Recurrence and Outcome According to Breast Cancer Subtypes in Lymph Node-Negative Disease: Results From International Breast Cancer Study Group Trials VIII and IX. J Clin Oncol. 1 sept 2013;31(25):3083 $\square 90$.

25. Lai C-H, Huang K-G, Hong J i-Hong, Lee C-L, Chou H-H, Chang T-C, et al. Randomized trial of surgical staging (extraperitoneal or laparoscopic) versus clinical staging in locally advanced cervical cancerts. Gynecol Oncol. 1 avr 2003;89(1):160 $\square 7$.

26. Gold MA, Tian C, Whitney CW, Rose PG, Lanciano R. Surgical versus radiographic determination of para-aortic lymph node metastases before chemoradiation for locally advanced cervical carcinoma: a Gynecologic Oncology Group Study. Cancer. 1 mai 2008;112(9):1954 663.

27. Leblanc E, Narducci F, Frumovitz M, Lesoin A, Castelain B, Baranzelli MC, et al. Therapeutic value of pretherapeutic extraperitoneal laparoscopic staging of locally advanced cervical carcinoma. Gynecol Oncol. mai 2007;105(2):304 $\square 11$.

28. Morice P, Rouanet P, Rey A, Romestaing P, Houvenaeghel G, Boulanger JC, et al. Results of the GYNECO 02 study, an FNCLCC phase III trial comparing hysterectomy with no hysterectomy in patients with a (clinical and radiological) complete response after chemoradiation therapy for stage IB2 or II cervical

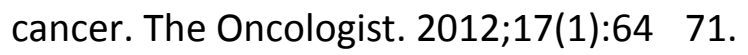

29. Lèguevaque $P$, Motton S, Delannes $M$, Querleu $D$, Soulé-Tholy $M$, Tap $G$, et al. Completion surgery or not after concurrent chemoradiotherapy for locally advanced cervical cancer? Eur J Obstet Gynecol Reprod Biol. avr 2011;155(2):188 $\square 92$.

30. Shim SH, Kim SN, Chae SH, Kim JE, Lee SJ. Impact of adjuvant hysterectomy on prognosis in patients with locally advanced cervical cancer treated with concurrent chemoradiotherapy: a meta-analysis. J Gynecol Oncol. mars 2018;29(2):e25. 
31. Legge F, Chiantera V, Macchia G, Fagotti A, Fanfani F, Ercoli A, et al. Clinical outcome of recurrent locally advanced cervical cancer (LACC) submitted to primary multimodality therapies. Gynecol Oncol. juill 2015;138(1):83 $\square$ 8.

32. Bodurka-Bevers D, Morris M, Eifel PJ, Levenback C, Bevers MW, Lucas KR, et al. Posttherapy surveillance of women with cervical cancer: an outcomes analysis. Gynecol Oncol. août 2000;78(2):187 $\square 93$.

33. Olaitan A, Murdoch J, Anderson R, James J, Graham J, Barley V. A critical evaluation of current protocols for the follow-up of women treated for gynecological malignancies: a pilot study. Int J Gynecol Cancer Off J Int Gynecol Cancer Soc. oct 2001;11(5):349 $\square 53$.

34. Zola P, Fuso L, Mazzola S, Piovano E, Perotto S, Gadducci A, et al. Could followup different modalities play a role in asymptomatic cervical cancer relapses diagnosis? An Italian multicenter retrospective analysis. Gynecol Oncol. oct 2007;107(1 Suppl 1):S150-154.

35. Zanagnolo V, Minig LA, Gadducci A, Maggino T, Sartori E, Zola P, et al. Surveillance procedures for patients for cervical carcinoma: a review of the literature. Int J Gynecol Cancer Off J Int Gynecol Cancer Soc. avr

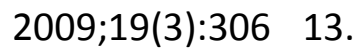

36. Hricak H, Powell CB, Yu KK, Washington E, Subak LL, Stern JL, et al. Invasive cervical carcinoma: role of MR imaging in pretreatment work-up--cost minimization and diagnostic efficacy analysis. Radiology. févr

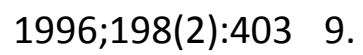

37. Jeong YY, Kang HK, Chung TW, Seo JJ, Park JG. Uterine cervical carcinoma after therapy: CT and MR imaging findings. Radiogr Rev Publ Radiol Soc N Am Inc. août 2003;23(4):969 $\square 81$; discussion 981.

38. Schwartz LB, Panageas E, Lange R, Rizzo J, Comite F, McCarthy S. Female pelvis: impact of MR imaging on treatment decisions and net cost analysis. Radiology. juill 1994;192(1):55 $\square 60$. 
39. Yamashita Y, Harada M, Torashima M, Takahashi M, Miyazaki K, Tanaka N, et al. Dynamic MR imaging of recurrent postoperative cervical cancer. J Magn Reson Imaging JMRI. févr 1996;6(1):167 $\square 71$.

40. Choi JI, Kim SH, Seong CK, Sim JS, Lee HJ, Do KH. Recurrent uterine cervical carcinoma: spectrum of imaging findings. Korean J Radiol. déc 2000;1(4):198 $\square 207$.

41. Chung HH, Kim S-K, Kim TH, Lee S, Kang KW, Kim J-Y, et al. Clinical impact of FDG-PET imaging in post-therapy surveillance of uterine cervical cancer: from diagnosis to prognosis. Gynecol Oncol. oct 2006;103(1):165 $\square 70$.

42. Ferrandina G, Legge F, Fagotti A, Fanfani F, Distefano M, Morganti A, et al. Preoperative concomitant chemoradiotherapy in locally advanced cervical cancer: safety, outcome, and prognostic measures. Gynecol Oncol. oct 2007;107(1 Suppl 1):S127-132. 
TABLES

Table 1: Epidemiological and histological characteristics of the whole population.

Characteristics

Age-median [range]

BMI kg/m2-median [range]

Post-menopausal patients [\%]

Tumor size on $\mathrm{MRI}, \mathrm{mm}$ - median

[range]

\section{Tumor histology}

-Squamous cell carcinoma [\%]

-Adenocarcinoma [\%]

Histological grade of the tumor

-Well differentiated [\%]

-Moderately differentiated [\%]

-Poorly differentiated [\%]

-Unclassified [\%]
Population

$\%$

$n=501$
54 [23-91]

$37[12-49]$

258 [51\%]

$45[2-95]$

426 [85\%]

75 [15\%]

149 [30\%]

129 [26\%]

81 [16\%]

$142[28 \%]$

83 [17\%]

69 [14\%]

FIGO classification

-IB2 [\%] 


\section{LVSI status}

-Positive [\%]

67 [13\%]

-Negative [\%]

$163[33 \%]$

-Unknown [\%]

$271[54 \%]$

\section{Treatments}

-CCRT +/- VBT

$222[44 \%]$

-CCRT +/- VBT followed by radical HT

$211[42 \%]$

-First radical HT +/- CCRT +/- VBT

$68[14 \%]$

\section{Radiological LN staging}

- Radiological staging by PET-scan

$300[60 \%]$

- No radiological staging by PET-scan

$201[40 \%]$

\section{Surgical LN staging}

-PL or PAL or PL+PAL

$359[72 \%]$

-No surgical staging

$142[28 \%]$

\section{Lymph node status}

-Node positive women

$161[32 \%]$

-Node negative women

$255[51 \%]$

-Women with unknown LN status

85 [17\%]

Abbreviations: BMI, Body Mass Index; MRI, Magnetic Resonance Imaging; FIGO, International Federation of Gynaecology and Obstetrics; LVSI, Lymphovascular Space Involvement; CCRT, concomitant ; VBT, vaginal brachytherapy; HT, hysterectomy; LN, 
lymph node; PET, Positron Emisson Tomography; PL, pelvic lymphadenectomy; PAL, para-aortic lymphadenectomy. 
Table 2: multivariate analysis for RFS and OS

\begin{tabular}{|c|c|c|c|c|c|c|}
\hline & \multicolumn{3}{|c|}{ RFS } & \multicolumn{3}{|c|}{ OS } \\
\hline & Coefficient & $\begin{array}{c}95 \% \\
\text { IC }\end{array}$ & $\mathbf{p}$ & Coefficient & $\begin{array}{c}95 \% \\
\text { IC }\end{array}$ & $\mathbf{p}$ \\
\hline \multicolumn{7}{|c|}{ FIGO classification } \\
\hline IB2 & \multicolumn{3}{|c|}{ = reference } & \multicolumn{3}{|c|}{ = reference } \\
\hline IIA & 1,4 & $\begin{array}{c}0,69 \\
- \\
2,96\end{array}$ & 0,32 & 0,7 & $\begin{array}{c}0,31 \\
- \\
1,82\end{array}$ & 0,47 \\
\hline IIB & 2,6 & $\begin{array}{l}1,48- \\
4,60\end{array}$ & $<0,001$ & 1,2 & $\begin{array}{c}0,68 \\
- \\
2,27\end{array}$ & 0,52 \\
\hline \multicolumn{7}{|c|}{ Lymph Node Status } \\
\hline $\begin{array}{l}\text { Node } \\
\text { negative } \\
\text { women }\end{array}$ & \multicolumn{3}{|c|}{ = reference } & \multicolumn{3}{|c|}{ = reference } \\
\hline $\begin{array}{l}\text { Node positive } \\
\text { women }\end{array}$ & 1,4 & $\begin{array}{c}0,90 \\
- \\
2,20\end{array}$ & 0,12 & 1,8 & $\begin{array}{l}1,00- \\
3,17\end{array}$ & $<0,05$ \\
\hline $\begin{array}{l}\text { Women } \\
\text { withunknown } \\
\text { LN status }\end{array}$ & 2,2 & $\begin{array}{c}1,49 \\
- \\
3,21\end{array}$ & $<0,001$ & 2,1 & $\begin{array}{l}1,24- \\
3,56\end{array}$ & $<0,01$ \\
\hline \multicolumn{7}{|l|}{ Treatments } \\
\hline CCRT +/- VBT & \multicolumn{3}{|c|}{ = reference } & \multicolumn{3}{|c|}{ = reference } \\
\hline CCRT +/- VBT & 0,7 & 0,47 & $<0,05$ & 0,8 & $0,51-$ & 0,35 \\
\hline
\end{tabular}




\begin{tabular}{|l|c|c|c|c|c|c|}
\hline $\begin{array}{l}\text { followed by } \\
\text { radical HT }\end{array}$ & $\begin{array}{c}- \\
0,97\end{array}$ & & & 1,28 & \\
\hline First radical & 0,7 & 0,38 & 0,18 & 0,3 & $0,11-$ & $<0,05$ \\
HT +/- CCRT & & - & & & 0,90 & \\
+/- VBT & & 1,19 & & & & \\
\hline
\end{tabular}

Abbreviations: FIGO, International Federation of Gynaecology and Obstetrics; CCRT, concomitant ; VBT, vaginal brachytherapy; HT, hysterectomy; RFS, recurrence free survival; OS, overall survival. 


\section{FIGURES}

Figure 1: Flow Chart of the study

Abbreviations: FIGO, International Federation of Gynaecology and Obstetrics.

Figure 2 A: Three-year cumulative incidence rates of loco regional recurrences according to FIGO stage

Figure 2 B: Three-year cumulative incidence rates of distant recurrences according to FIGO stage

Figure 2 C: Three-year cumulative incidence rates of loco regional recurrences according to $\mathrm{LN}$ status

Figure 2 D: Three-year cumulative incidence rates of distant recurrences according to LN status

Figure 2 E: Three-year cumulative incidence rates of loco regional recurrences according to treatment modalities

Figure 2 F: Three-year cumulative incidence rates of distant recurrences according to treatment modalities

Abbreviations: FIGO, International Federation of Gynaecology and Obstetrics; LN, lymph node; $\mathrm{N}+$, Node positive women; $\mathrm{N}-$, Node negative women; CCRT, concomitant ; VBT, vaginal brachytherapy; HT, hysterectomy 
Figure 1

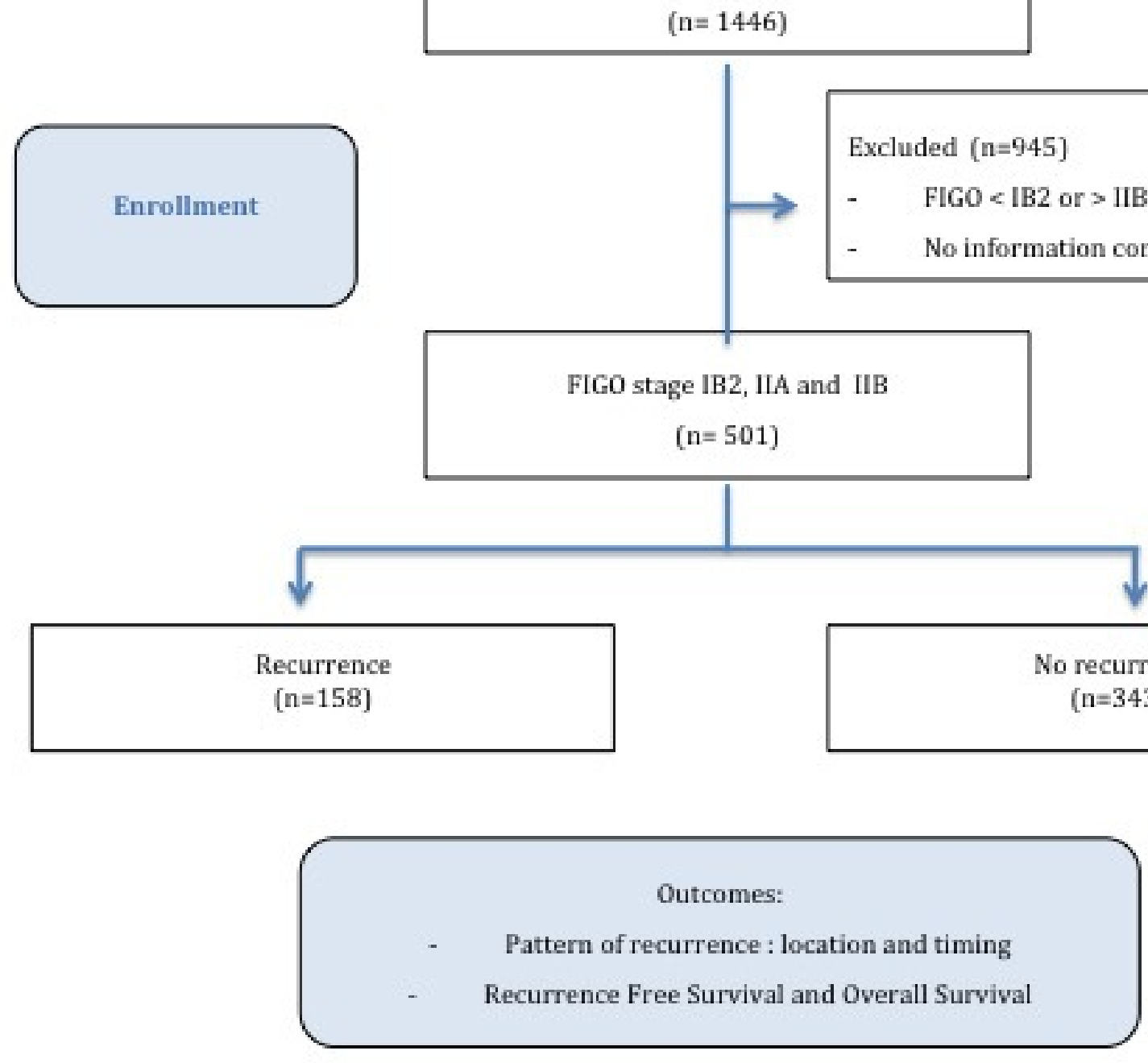



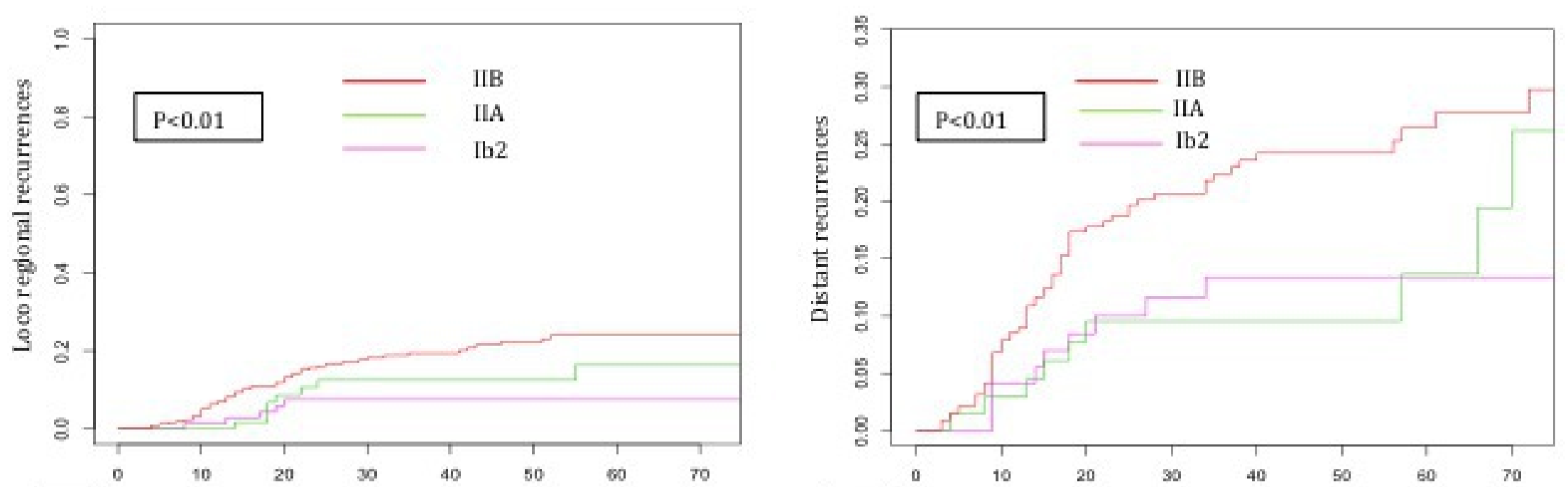

A Time (months]

B

Time (months)
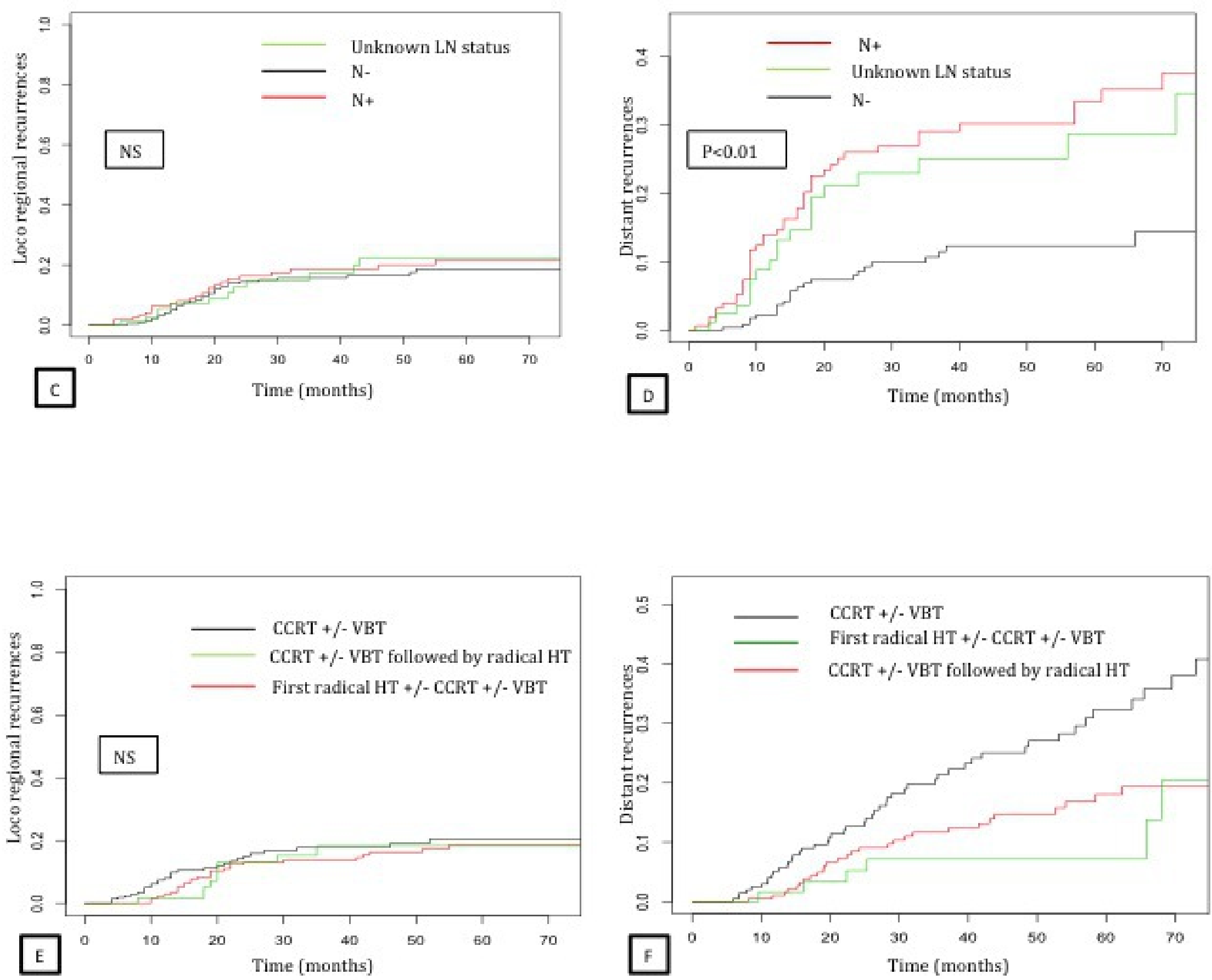

Figure 2 